University of Nebraska - Lincoln

DigitalCommons@University of Nebraska - Lincoln

Wheat streak mosaic virus genotypes introduced to Argentina are closely related to isolates from the American Pacific Northwest and Australia

\author{
Drake C. Stenger \\ USDA-ARS, drake.stenger@ars.usda.gov \\ Roy French \\ USDA-ARS
}

Follow this and additional works at: https://digitalcommons.unl.edu/usdaarsfacpub

Part of the Agricultural Science Commons

Stenger, Drake C. and French, Roy, "Wheat streak mosaic virus genotypes introduced to Argentina are closely related to isolates from the American Pacific Northwest and Australia" (2009). Publications from USDA-ARS / UNL Faculty. 793.

https://digitalcommons.unl.edu/usdaarsfacpub/793

This Article is brought to you for free and open access by the U.S. Department of Agriculture: Agricultural Research Service, Lincoln, Nebraska at DigitalCommons@University of Nebraska - Lincoln. It has been accepted for inclusion in Publications from USDA-ARS / UNL Faculty by an authorized administrator of DigitalCommons@University of Nebraska - Lincoln. 


\title{
Wheat streak mosaic virus genotypes introduced to Argentina are closely related to isolates from the American Pacific Northwest and Australia
}

\author{
Drake C. Stenger · Roy French
}

Received: 3 November 2008/Accepted: 2 December 2008/Published online: 9 January 2009

(C) US Government 2009

\begin{abstract}
Wheat streak mosaic virus (WSMV) was first detected in Argentina in 2002. Comparison of 78 WSMV coat protein sequences revealed that three Argentine isolates were closely related to isolates from the American Pacific Northwest (APNW) and Australia. Complete sequences were determined for one Argentine isolate, four APNW isolates, and three additional isolates from other regions of the USA. Comparison of these eight new sequences with five previously sequenced isolates of WSMV confirmed close affinity of WSMV from Argentina with APNW isolates. Collectively, these results indicate concurrent establishment of the same WSMV lineage in both Argentina and Australia.
\end{abstract}

Wheat streak mosaic virus (WSMV) is the type species of the genus Tritimovirus in the family Potyviridae [17]. First reported from the Central Great Plains of the USA in the 1920s [12], WSMV is widely distributed in wheat-growing regions of North America and Eurasia. Previous phylogenetic analyses [14, 18] grouped WSMV isolates into four distinct clades. Clade A, represented by the El Batán 3 isolate from Mexico [15], differs in nucleotide sequence from the other three clades by $\sim 20 \%$ [1]. WSMV isolates from Central Europe and Russia [14] comprise Clade B and differ in nucleotide sequence from Clade $\mathrm{C}$ and $\mathrm{D}$

\section{C. Stenger · R. French}

United States Department of Agriculture,

Agricultural Research Service, 344 Keim Hall,

University of Nebraska, Lincoln, NE 68583, USA

Present Address:

D. C. Stenger $(\square)$

USDA-ARS, San Joaquin Valley Agricultural Sciences Center,

9611 South Riverbend Road, Parlier, CA 93648, USA

e-mail: drake.stenger@ars.usda.gov genotypes by $\sim 10 \%$. An isolate from Iran [14] represents Clade C, differing in sequence from Clade $\mathrm{D}$ genotypes by $\sim 8 \%$. Numerous WSMV isolates from temperate North America belong to Clade D and share $>96 \%$ nucleotide sequence identity. Clade D also includes two isolates from Turkey, suggesting intercontinental movement at some time in the past [14].

WSMV in Australia was first detected in greenhousegrown wheat germplasm in 2002 and soon thereafter was found in several Australian wheat-growing regions [3]. Analysis of 3'-proximal partial nucleotide sequences [2] indicated that Australian isolates of WSMV were closely related to each other, and also to certain Clade D isolates from the American Pacific Northwest (APNW). As several of the Australian isolates are seed borne in wheat at low frequency $[2,11]$, infected seed has been implicated as the means of initial introduction. Subsequent spread of WSMV within Australia was likely due to both seed transmission and vector transmission by the wheat curl mite [8].

In contrast to the establishment of WSMV in Australia, introduction of WSMV to Argentina is less well documented. WSMV was first detected in Argentina in 2002 [19] by symptom expression in field grown wheat in the Cordoba province; identity of the virus was verified by reverse transcription-polymerase chain reaction (RT-PCR). However, the relationship of WSMV genotypes from Argentina with those occurring elsewhere in the world is unknown. Here, we report phylogenetic placement of three Argentine isolates of WSMV, based on coat protein (CP) gene sequences. Subsequently, we confirmed phylogenetic placement of WSMV from Argentina via complete sequence comparisons of 1 Argentine isolate with 12 completely sequenced WSMV isolates (7 of which are reported for the first time here) from the USA, Mexico, and Eurasia. 
The origins of WSMV isolates used in sequence comparisons are listed in Table 1. Total nucleic acid samples for Argentine isolates Arg1, Arg2, and Arg3 were extracted [13] from systemically infected wheat leaves ( $\sim 2 \mathrm{~g})$. Complementary DNA was synthesized by RT using the primer RCF1 (5'-AGCTGGATCCTTTTTTTTTTTTTTT-3') [13]. A 1,267-bp fragment was amplified by PCR using the primers XV1 (5'-GATTCCGTTGAAGGATTTGTA ACTT- $\left.3^{\prime}\right)$ and $\mathrm{XC1}$ (5'-AACCCACACATAGCTACCA AG-3') [6]. The amplified products correspond to WSMVSidney 81 nts 8,105-9,371 [17], encompassing the entire CP coding region (nts 8,189-9,238) and flanked upstream by the $3^{\prime}$-proximal portion of the nuclear inclusion $b$ coding region and downstream by $3^{\prime}$-untranslated sequences. The amplicons were gel purified and cloned into pGEM-Teasy (Promega, Madison, WI). For each Argentine isolate, a consensus sequence was generated based on three independent clones per isolate.

Complete CP gene nucleotide sequences for 78 WSMV isolates (Table 1) and an isolate of Oat necrotic mottle virus (ONMV; GenBank accession number AY377938), the most closely related tritimovirus species [16], were aligned using CLUSTAL X. Neighbor-joining analysis was performed using CLUSTAL $X$ with 1,000 bootstrap iterations; gaps were excluded from the analysis, and all other parameters were set to default values. The resulting tree (Fig. 1) was visualized using the TreeView program, with all nodes having less than $60 \%$ bootstrap support collapsed to polytomies, and rooted with ONMV designated as the outgroup. CP gene sequences of the three Argentine isolates clustered in Clade D. Although Clade D is mostly unstructured, significant bootstrap support existed for at least four subclades ('Sidney', 'Type', 'APNW', and a fourth lacking a single proline codon and including isolate H95S) as described previously [18]. Interestingly, the three Argentine isolates shared a node with high bootstrap support $(>86 \%)$ in common with and exclusive to 15 Australian isolates and four APNW isolates (ID96, ID99, WA94, and WA99). It should be noted that the positions of ID99 and Mon96 in the present analysis (Fig. 1) are reversed (e.g., ID99 and not Mon96 is part of the APNW subclade) relative to the tree presented previously [18], as these two nucleotide sequences were mutually mislabeled for GenBank submission and in the original analysis of 2002. The GenBank accessions for these two isolates have since been corrected.

To verify relationships inferred by neighbor-joining analysis of CP sequences presented in Fig. 1, the same data set was evaluated using the maximum-likelihood method. A tree was generated using Treefinder with the HKY model of nucleotide substitution and 200 bootstrap replicates [10]. The topology of the $\mathrm{CP}$ tree generated by maximum likelihood was identical to the neighbor-joining tree of Fig. 1 with respect to isolates from Argentina, Australia, and the APNW sharing a common node (bootstrap value $=86 \%$ ) exclusive of all other taxa examined (data not shown).

To further confirm phylogenetic placement of WSMV from Argentina, the complete sequences of one Argentine isolate (Arg2) and seven isolates from the USA were determined. The American isolates were selected for complete sequencing based on known affinity with the APNW subclade (ID96, ID99, WA94 and WA99), a representative member of the subclade sharing a single proline codon deletion (H95S), and two arbitrary draws (H98 and Mon96) from the unstructured portion of clade D. Australian isolates were not available for complete sequencing. For each isolate, total nucleic acid samples were extracted as described above. RT was conducted using a mixture of RCF1 and random hexamer primers. Complementary DNA was used as template in PCR with the following primer sets to amplify each genome in overlapping "thirds" corresponding to WSMVSidney81 nucleotide coordinates: nts 1-3618 (5'-GGA TCCATTTAGGTGACACTATAGAAA TTAAACCAAC CCAAA TC- $3^{\prime}$ and $5^{\prime}$-CCGGATCCTATTCAACCAATT C-3'), nts 2,339-6,691 (5'-CCGGATCCGGGTTCCAAG AGACTGTT- $3^{\prime}$ and $5^{\prime}$-GACTTCTAGATCATTGCCAA CTAACCAAG-3'), and nts 5,414-9,384 (5'-GTCTAA GCTTGGGCAAAGCAGCACGCA- $3^{\prime}$ and RCF1), with $3^{\prime}$-proximal nucleotides in bold corresponding to WSMVSidney 81 plus or minus sense sequences. In cases where no product was amplified with a given primer set, alternative primers were utilized such that overlap among amplified "thirds" of the genome was maintained. PCR products were cloned into pGEM-Teasy and three independent clones were sequenced for each. Consensus sequences for each complete genome were compiled using DNA Sequencher 4.1.

The eight complete nucleotide sequences determined in this study were aligned with five previously sequenced isolates of WSMV (Sidney81, Type, Czech, TK1, and El Batán 3) and the complete genome of ONMV. Neighborjoining analysis was performed on the aligned complete sequences as described above, and the resulting tree (Fig. 2) was rooted using ONMV as the outgroup; all nodes having less than $60 \%$ bootstrap support were collapsed to polytomies. The complete sequence of Arg2 was most closely related to isolate ID96 (98.9\% nucleotide sequence identity) and shared a node exclusive to and in common with all four completely sequenced isolates from the APNW. Complete sequences of Australian WSMV isolates were unavailable for comparison.

The 13 WSMV complete sequences also were used to generate alignments of individual gene sequences (P1, HCPro, P3, CI, NIa, and NIb) and subjected to neighborjoining analysis (as described above); ONMV was used as the outgroup. In all cases, tree topology was identical (data 
Table 1 Wheat streak mosaic virus (WSMV) isolates used in sequence comparisons

\begin{tabular}{|c|c|c|c|}
\hline WSMV isolate & Accession number & Geographic Origin & Reference \\
\hline Sidney $81^{\mathrm{a}}$ & AF057533 & Nebraska, USA & [17] \\
\hline Type $^{\mathrm{a}}$ & AF285169 & Kansas, USA & [1] \\
\hline El Batán $3^{\mathrm{a}}$ & AF285170 & Mexico & [1] \\
\hline Czech $^{\mathrm{a}}$ & AF454454 & Czech Republic & [14] \\
\hline Hungary & AF454456 & Hungary & [14] \\
\hline Russia & AF454459 & Russia & {$[14]$} \\
\hline Iran & AF454458 & Iran & [14] \\
\hline $\mathrm{TK} 1^{\mathrm{a}}$ & AF454455 & Turkey & [14] \\
\hline TK2 & AF454457 & Turkey & [14] \\
\hline $\mathrm{H} 95 \mathrm{~S}^{\mathrm{a}}$ & AF511614 & Kansas, USA & This study ${ }^{\mathrm{b}}$ \\
\hline $\mathrm{H} 98^{\mathrm{a}}$ & AF511615 & Kansas, USA & This study ${ }^{\mathrm{b}}$ \\
\hline${\text { ID } 96^{\mathrm{a}}}$ & AF511618 & Idaho, USA & This study ${ }^{b}$ \\
\hline${\text { ID } 99^{\mathrm{a}}}$ & AF511619 & Idaho, USA & This study ${ }^{b}$ \\
\hline Mon96 ${ }^{\mathrm{a}}$ & AF511630 & Montana, USA & This study ${ }^{b}$ \\
\hline WA94 ${ }^{\mathrm{a}}$ & FJ348358 & Washington, USA & This study \\
\hline WA99 ${ }^{\mathrm{a}}$ & AF511643 & Washington, USA & This study $^{\mathrm{b}}$ \\
\hline Arg 1 & FJ348356 & Argentina & This study \\
\hline $\operatorname{Arg} 2^{\mathrm{a}}$ & FJ348359 & Argentina & This study \\
\hline Arg 3 & FJ348357 & Argentina & This study \\
\hline Mt. Burdett & DQ888801 & Australia & [2] \\
\hline Yerritup & DQ888802 & Australia & {$[2]$} \\
\hline Gibson & DQ888803 & Australia & [2] \\
\hline Galong & DQ888804 & Australia & {$[2]$} \\
\hline Kondonin & DQ888805 & Australia & {$[2]$} \\
\hline SP-5 & DQ462276 & Australia & {$[2]$} \\
\hline SP-6 & DQ462277 & Australia & {$[2]$} \\
\hline Tamworth1 & AY327866 & Australia & Mago et al., unpublished \\
\hline Tamworth2 & AY327867 & Australia & Mago et al., unpublished \\
\hline Adelaide1 & AY327868 & Australia & Mago et al., unpublished \\
\hline Adelaide2 & AY327869 & Australia & Mago et al., unpublished \\
\hline Canberra & AY327865 & Australia & Mago et al., unpublished \\
\hline MurrayBridge & AY327872 & Australia & Mago et al., unpublished \\
\hline Horsham & AY327871 & Australia & Mago et al., unpublished \\
\hline Bordertown & AY327870 & Australia & Mago et al., unpublished \\
\hline Ger & AJ889242 & Germany & Shi et al., unpublished \\
\hline PV57 & AF511595 & Kansas, USA & [18] \\
\hline S81D & AF511596 & Nebraska, USA & [18] \\
\hline CK93 & AF511598 & Kansas, USA & [18] \\
\hline CL93 & AF511599 & Kansas, USA & [18] \\
\hline CM93 & AF511600 & Kansas, USA & {$[18]$} \\
\hline CO85 & AF511601 & Colorado, USA & {$[18]$} \\
\hline CO87 & AF511602 & Colorado, USA & [18] \\
\hline EW95 & AF511603 & Kansas, USA & {$[18]$} \\
\hline FO93 & AF511604 & Kansas, USA & [18] \\
\hline GH95 & AF511605 & Kansas, USA & {$[18]$} \\
\hline GO93 & AF511606 & Kansas, USA & [18] \\
\hline GY93 & AF511607 & Kansas, USA & [18] \\
\hline H81 & AF511608 & Kansas, USA & [18] \\
\hline
\end{tabular}


Table 1 continued

\begin{tabular}{|c|c|c|c|}
\hline WSMV isolate & Accession number & Geographic Origin & Reference \\
\hline H88 & AF511609 & Kansas, USA & {$[18]$} \\
\hline H94PM & AF511610 & Kansas, USA & {$[18]$} \\
\hline $\mathrm{H} 94 \mathrm{~S}$ & AF511611 & Kansas, USA & {$[18]$} \\
\hline H94USDA & AF511612 & Kansas, USA & {$[18]$} \\
\hline H95LB & AF511613 & Kansas, USA & {$[18]$} \\
\hline HM93 & AF511616 & Kansas, USA & {$[18]$} \\
\hline HV91 & AF511617 & Kansas, USA & {$[18]$} \\
\hline IHC & AF511620 & Canada & {$[18]$} \\
\hline KM93 & AF511621 & Kansas, USA & {$[18]$} \\
\hline KY00 & AF511622 & Kentucky, USA & {$[18]$} \\
\hline KY0074 & AF511623 & Kentucky, USA & {$[18]$} \\
\hline KY0083SV & AF511624 & Kentucky, USA & {$[18]$} \\
\hline LC95 & AF511625 & Kansas, USA & {$[18]$} \\
\hline LG92 & AF511626 & Kansas, USA & {$[18]$} \\
\hline MO99A & AF511627 & Missouri, USA & {$[18]$} \\
\hline MO99B & AF511628 & Missouri, USA & {$[18]$} \\
\hline MO00 & AF511629 & Missouri, USA & {$[18]$} \\
\hline ND & AF511631 & North Dakota, USA & {$[18]$} \\
\hline NE96 & AF511632 & Nebraska, USA & {$[18]$} \\
\hline OK98 & AF511633 & Oklahoma, USA & {$[18]$} \\
\hline OSU & AF511634 & Unknown & {$[18]$} \\
\hline PL95 & AF511635 & Kansas, USA & {$[18]$} \\
\hline PN95 & AF511636 & Kansas, USA & {$[18]$} \\
\hline PV106H & AF511637 & Ohio, USA & {$[18]$} \\
\hline PV106JM & AF511638 & Ohio, USA & {$[18]$} \\
\hline PV91H & AF511639 & Kansas, USA & {$[18]$} \\
\hline RO95 & AF511640 & Kansas, USA & {$[18]$} \\
\hline SD96 & AF511641 & South Dakota, USA & {$[18]$} \\
\hline TX96 & AF511642 & Texas, USA & {$[18]$} \\
\hline WO93 & AF511644 & Ohio, USA & [18] \\
\hline
\end{tabular}

${ }^{\text {a }}$ Complete nucleotide sequence

b 3 -proximal sequences reported in [18]

not shown) to that of Fig. 2 with respect to isolate $\operatorname{Arg} 2$ sharing a node in common with and exclusive to the four APNW isolates. Bootstrap values (based on 1,000 iterations) for the basal node of the Arg2/APNW lineage were 910 (P1), 842 (HC-Pro), 673 (P3), 994 (CI), 982 (NIa), and 718 (NIb).

WSMV isolates from Argentina, Australia, and the APNW clearly constitute a single lineage (subclade) within Clade D. Limited sequence variation among the Australian and Argentine isolates was observed. This is not unexpected as separate introductions to geographically isolated regions should result in founder effect bottlenecks followed by population expansion. Furthermore, variation within each recently established population is not surprising as WSMV lineages have been shown to accumulate independent changes in consensus sequence upon passage from plant to plant [7]. Given that most changes in consensus sequence of a WSMV isolate upon passage are stochastic, due to small effective population sizes resulting from bottlenecks during systemic movement and plant-to-plant transmission $[4,5,7]$, variation encountered within and between the Argentine and Australian populations likely reflects genetic drift rather than differential selection.

Why has this same WSMV lineage recently invaded two isolated wheat-growing regions on separate continents? Given that Clade D is a large polytomy with 38 branches at the basal node (Fig. 1), it is unlikely that two random draws from Clade D would share the same branch. There are two non-exclusive explanations for the recent intercontinental dispersion of this lineage: (1) It was introduced from a common source and/or (2) this particular lineage is seed borne at a rate greater than that of other WSMV 
Fig. 1 Phylogenetic relationships among coat protein $(\mathrm{CP})$ gene nucleotide sequences of 78 wheat streak mosaic virus (WSMV) isolates. Presented is a neighbor-joining tree based on 1,000 bootstrap iterations and rooted with the $\mathrm{CP}$ sequence of oat necrotic mottle virus (ONMV) designated as the outgroup. Bootstrap values for nodes with high support $(\geq 60 \%)$ are indicated on branches basal to each node; nodes bearing $<60 \%$ bootstrap support were collapsed to polytomies. WSMV Clades A-D are labeled at the respective basal branch defining each clade. WSMV isolates from the American Pacific Northwest (APNW), Australia, and Argentina shared a common node exclusive of all other taxa and are labeled on the right. Branch lengths are proportional to genetic distance; length of scale bar at lower left corresponds to a genetic distance of 0.1

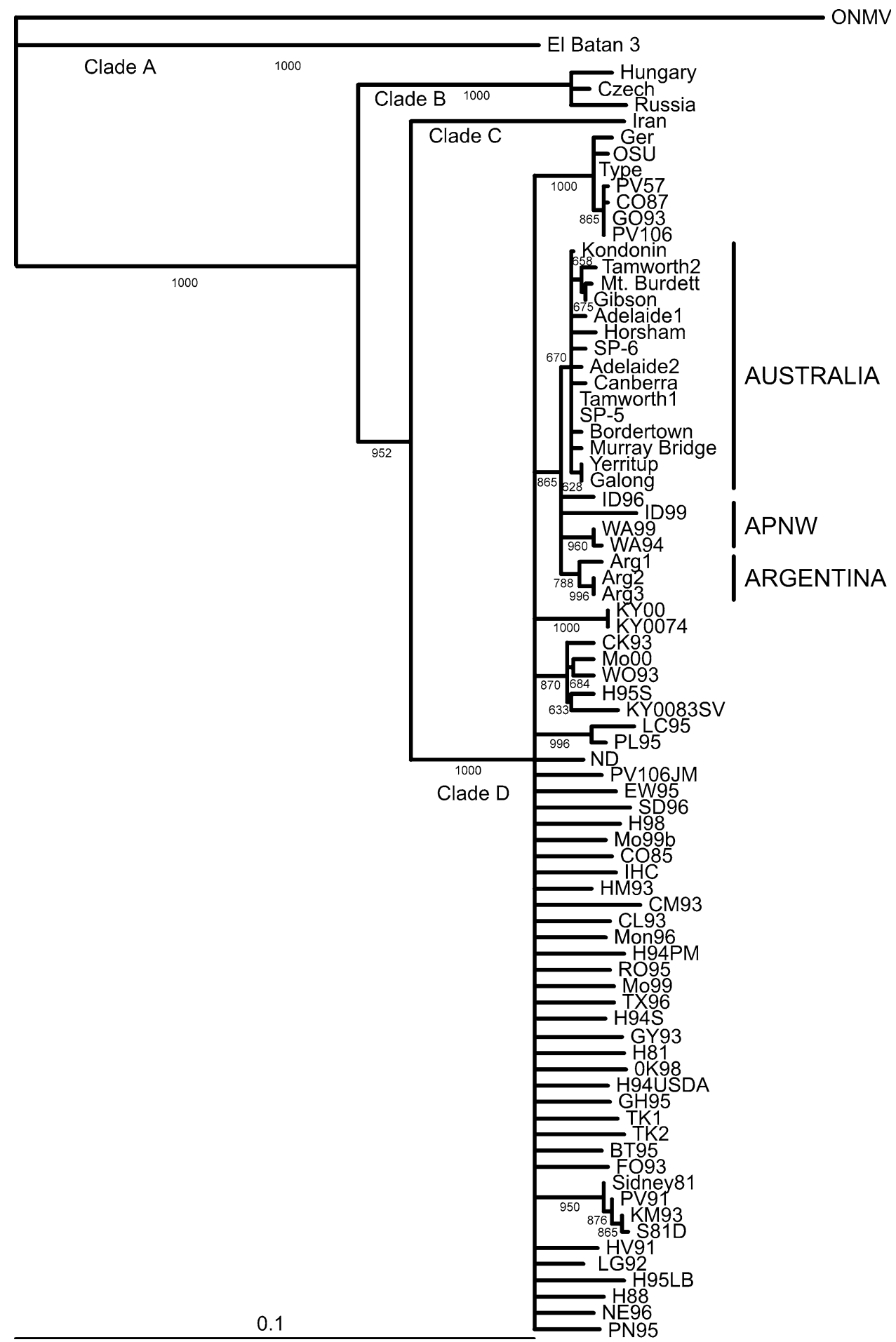

lineages. With respect to the first explanation, the lineage in question has been present in the APNW since at least 1994 (the earliest year of collection of isolates belonging to the lineage), 8 years before detection of WSMV in Australia and Argentina. However, the first isolations of WSMV in Australia were from greenhouse-grown wheat breeding lines derived from Centro Internacional de
Mejoramiento de Maiz y Trigo (CIMMYT) in Mexico [3]. Furthermore, absence of data does not demonstrate that this lineage was not present in other locations that could have served as a source. With respect to the second explanation, WSMV isolates from Australia are seed borne at $0.5-2 \%$ $[2,11]$, a rate several $\log$ units greater than that previously reported for WSMV in maize [9]. However, as other 


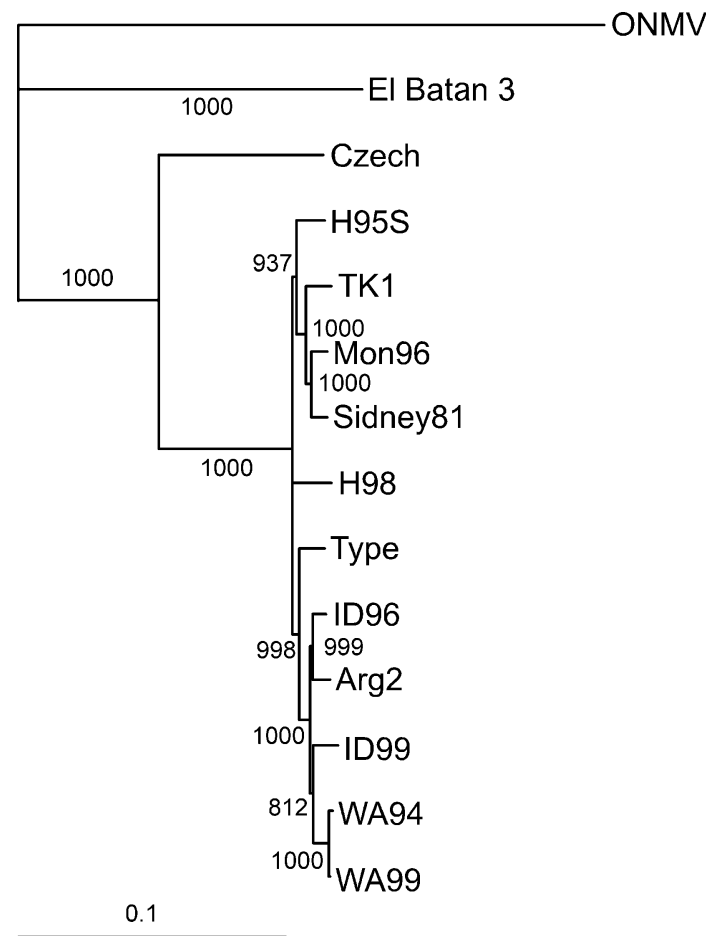

Fig. 2 Phylogenetic relationships among complete nucleotide sequences of 13 wheat streak mosaic virus (WSMV) isolates. Presented is a neighbor-joining tree based on 1,000 bootstrap iterations and rooted with the complete sequence of oat necrotic mottle virus (ONMV) designated as the outgroup. Bootstrap values for nodes with high support $(\geq 60 \%)$ are indicated on branches basal to each node; nodes bearing $<60 \%$ bootstrap support were collapsed to polytomies. Branch lengths are proportional to genetic distance; length of scale bar at lower left corresponds to a genetic distance of 0.1. Note that the WSMV isolate from Argentina (Arg2) shared a node exclusive to and in common with four isolates (ID96, ID99, WA94, and WA99) from the American Pacific Northwest

lineages of WSMV have not been evaluated for seed transmission, it remains unclear whether a rate of $\sim 1 \%$ is unusual. Thus, while both explanations are plausible, neither can be validated or excluded at this time.

Acknowledgments We thank G. Truol for kindly providing WSMV isolates Arg1, Arg2, and Arg3, and Kathryn Stenberg and Brock Young for technical assistance. Mention of proprietary or brand names is necessary to report factually on available data; however, the USDA neither guarantees nor warrants the standard of the product, and the use of the name by USDA implies no approval to the exclusion of others that also may be suitable. This article is in the public domain and not copyrightable. It may be freely reprinted with customary crediting of source.

\section{References}

1. Choi I-R, Hall JS, Henry M, Zhang L, Hein GL, French R, Stenger DC (2001) Contributions of genetic drift and negative selection on the evolution of three strains of wheat streak mosaic tritimovirus. Arch Virol 146:619-628

2. Dwyer GI, Gibb MJ, Gibbs AJ, Jones RAC (2007) Wheat streak mosaic virus in Australia: relationship to isolates from the Pacific Northwest of the USA and its dispersion via seed transmission. Plant Dis 91:164-170

3. Ellis MH, Rebetzke GJ, Mago R, Chu P (2003) First report of wheat streak mosaic virus in Australia. Australas Plant Pathol 32:551-553

4. French R, Stenger DC (2003) Evolution of wheat streak mosaic virus: dynamics of population growth within plants may explain limited variation. Ann Rev Phytopathol 41:199-214

5. French R, Stenger DC (2005) Population structure within lineages of Wheat streak mosaic virus derived from a common founding event exhibits stochastic variation inconsistent with the deterministic quasi-species model. Virology 343:179-189

6. Hall JS, French R, Hein GL, Morris TJ, Stenger DC (2001a) Three distinct mechanisms facilitate genetic isolation of sympatric wheat streak mosaic virus lineages. Virology 282:230-236

7. Hall JS, French R, Morris TJ, Stenger DC (2001b) Structure and temporal dynamics of populations within wheat streak mosaic virus isolates. J Virol 75:10231-10243

8. Halliday RB (2004) The occurrence of Aceria tulipae (Keifer) and Aceria tosichella Keifer in Australia. Int J Aracol 30:113118

9. Hill JH (1974) Seed transmission of maize dwarf mosaic and wheat streak mosaic viruses in maize and response of inbred lines

10. Jobb G, Von Haeseler A, Strimmer K (2004) TREEFINDER: a powerful graphical analysis environment for molecular phylogenetics. BMC Evol Biol 4, art no 18

11. Jones RAC, Coutts BA, Mackie AE, Dwyer GI (2006) Seed transmission of wheat streak mosaic virus shown unequivocally in wheat. Plant Dis 89:1048-1050

12. McKinney HH (1937) Mosaic diseases of wheat and related cereals. US Department of Agriculture Circular No 442

13. McNeil JE, French R, Hein GL, Baenziger PS, Eskridge KM (1996) Characterization of genetic variability among natural populations of wheat streak mosaic virus. Phytopathology 86: 1222-1227

14. Rabenstein F, Seifers DL, Schubert J, French R, Stenger DC (2002) Phylogenetic relationships, strain diversity and biogeography of tritimoviruses. J Gen Virol 83:895-906

15. Sánchez-Sánchez H, Henry M, Cárdenas Soriano E, Alvizo Villasana H (2001) Identification of wheat streak mosaic virus and its vector Aceria tosichella Keifer in Mexico. Plant Dis 85:13-17

16. Stenger DC, French R (2004) Complete nucleotide sequence of Oat necrotic mottle virus: a distinct Tritimovirus species (family Potyviridae) most closely related to Wheat streak mosaic virus. Arch Virol 149:633-640

17. Stenger DC, Hall JS, Choi I-R, French R (1998) Phylogenetic relationships within the family Potyviridae: wheat streak mosaic virus and brome streak mosaic virus are not members of the genus Rymovirus. Phytopathology 88:782-787

18. Stenger DC, Seifers DL, French R (2002) Patterns of polymorphism in Wheat streak mosaic virus: sequence space explored by a clade of closely related viral genotypes rivals that between the most divergent strains. Virology 302:58-70

19. Troul G, French R, Sagadin M, Arneodo J (2004) First report of wheat streak mosaic virus infecting wheat in Argentina. Aust Plant Pathol 33:137-138 